\title{
PRÁCTICA SOCIAL, SABER MÉDICO Y REFLEJO LITERARIO DE LA CULTURA DEL BAÑO EN EL CONTEXTO CATALAN MEDIEVAL ${ }^{1}$
}

\author{
SOCIAL PRACTICE, MEDICAL KNOWLEDGE AND LITERARY REFLECTIONS \\ OF THE BATHING CULTURE IN THE MEDIEVAL CATALAN CONTEXT
}

\section{Lluís Cifuentes; ANTÒNIA CARRÉ Centre de Documentació Ramon Llull Universitat de Barcelona}

\begin{abstract}
Resumen: En el contexto catalán de los últimos siglos medievales, la cultura del baño, especialmente del baño termal, terapéutico, pero también del baño frío, fue ocasión, sobre todo entre las élites, para la sociabilidad, bendecida por el apoyo de la prestigiosa medicina universitaria, pero también dio lugar a constantes ataques de los moralistas, mientras todo ello proporcionaba abundante material para la creación literaria. Las características del mercado de demanda de literatura médica explicarían la ausencia de una tratadística médica especializada en el particular durante este período.
\end{abstract}

Palabras clave: Baños; Termalismo; Sociabilidad; Medicina; Literatura.

\begin{abstract}
Bathing, particularly thermal baths, which were therapeutic, but also cold baths, became an occasion for social gatherings in late-medieval Catalonia, especially among the elite. It had the sanction of the prestigious university medicine, but it was nevertheless an activity condemned by moralists, a situation that is frequently reflected in literary works. The characteristics of the medical literature market account for the absence of specialised treatises on this subject during this period.
\end{abstract}

Keywords: Bathing; Thermalism; Sociability; Medicine; Literature.

\section{SUMARIO}

1. Los baños termales en la Corona de Aragón.- 1.1. La Corona de Aragón y la medicalización del baño.- 1.2. Los baños termales catalanes.- 1.3. Tratados médicos sobre los baños.- 2 . Difusión social y reflejo literario.- 2.1. Reflejo literario de la cultura del baño en el contexto románico.- 2.2. Los baños en la literatura catalana medieval.- 3. Epílogo: decadencia y cambio durante el Renacimiento.

\footnotetext{
${ }^{1}$ Una primera versión de este trabajo fue presentada en la mesa redonda sobre Constitution, diffusion et usage d'un savoir médical sur le thermalisme, organizada por Marilyn Nicoud y Didier Boisseuil (Aviñón, 2 de diciembre de 2005).

Este trabajo se inscribe en el marco del proyecto de investigación financiado por el Ministerio de Ciencia e Innovación (MICINN) Sciència.cat: hacia un corpus digital de la ciencia y de la técnica en catalán en la Edad Media y el Renacimiento (FFI2008-02163/FISO), dir. por Lluís Cifuentes, Univ. de Barcelona, véase www.sciencia.cat); y en el grupo de investigación consolidado por el Departament d'Innovació, Universitats 1 Empresa de la Generalitat de Catalunya Grup de cultura i literatura a la Baixa Edat Mitjana (SGR2005-00346, dir. por Lola Badia, UB, véase www.narpan.net).
} 
El baño, en tanto que ámbito privilegiado para la sociabilidad, ocasión para la higiene corporal y práctica indicada para la prevención y la terapéutica de las enfermedades, constituye históricamente el nexo de unión de diferentes actividades humanas, individuales y colectivas, que no podía dejar de atraer la atención de autores, estamentos e instituciones diversas. Una atención que explica su gran auge en algunas épocas y contextos, especialmente en la Antigüedad grecorromana, en el mundo islámico y en la Europa latina medieval, pero también su represión, hasta prácticamente eliminarlo, en otras.

Esta auténtica cultura del baño tenía su máxima expresión en el aprovechamiento de los manantiales de aguas calientes naturales, que el Occidente medieval, heredero de las civilizaciones antigua e islámica, medicalizó con especial atención. A diferencia de los baños de aguas frías, los baños termales se mantuvieron en uso, más o menos languideciente, tras el hundimiento del mundo antiguo, hasta encontrar un nuevo y decidido apoyo en la nueva medicina universitaria bajomedieval ${ }^{2}$.

Nuestro trabajo se centrará en la plasmación de este fenómeno en el área de la antigua Corona de Aragón y, más en particular, en Cataluña, durante los siglos XIV y XV, con especial atención a los problemas que presenta su reflejo en la tratadística médica y en la literatura de creación.

\section{LOS BAÑOS TERMALES EN LA CORONA DE ARAGÓN}

\subsection{La Corona de Aragón y la medicalización del baño}

Durante la Baja Edad Media, en la Corona de Aragón, monarquía, nobleza y burguesía demostraron una muy especial sensibilidad por la medicina y la salud, y todo lo relacionado con éstas. Se ha destacado su decidido apoyo a la institución universitaria y al modelo de medicina y de médico que de ella emanaban, la introducción de una legislación favorable a estos hechos, o el convertir, en suma, a la salud no ya en un privilegio de las élites sino en un bien social a proteger. Todo ello, hoy bien conocido gracias a los valiosos estudios realizados en las últimas décadas, no debe extrañarnos. ${ }^{3}$

\footnotetext{
${ }^{2}$ Véase una reciente presentación general del tema en el volumen monográfico sobre Le bain: espaces et pratiques dirigido por D. BOISSEUIL en "Medievales: Langue, textes, histoire", 43
(2002). Para el contexto périco, véase la síntesis de F. GIRÓN IRUESTE, Uso médico del agua en el mundo hispánico bajo medieval (siglos XII-XV), en F. MARAVER EYZAGUIRRE (coord.), Establecimientos balnearios: historia, literatura y medicina, Madrid, Universidad Complutense de Madrid, 2006, p. 79-95.

${ }^{3}$ Véase A. CARDONER I PLANAS, Història de la medicina a la Corona d'Aragó (1162-1479), Barcelona, Scientia, 1973; y, más actualizados, los trabajos de L. GARCÍA BALLESTER, La medicina a la València medieval: medicina $i$ societat en un país medieval mediterrani, Valencia, $\mathrm{Ed}$. Alfons el Magnànim (IVEI) [trad. esp. en: Estudios sobre la profesión médica en la sociedad valenciana (1329-1898), Valencia, Universitat de València, 1998]; M. R. MCVAUGH. Medicine before the Plague: Practitioners and Their Patients in the Crown of Aragon (1285-1345), Cambridge, Cambridge University Press, 1993; y C. FERRAGUD DOMINGO, Medicina i promoció social a Pa Baixa Edat Mitjana (Corona d'Arago, 1350-1410), Madrid, CSIC (Estudios sobre la ciencia, 36), 2005. Una breve síntesis en J. ARRIZABALAGA y Ll. CifUENTES, La medicina:
} 
En efecto, la antigua Confederación de catalanes y aragoneses surgió en la primera mitad del siglo XII precisamente en el arco mediterráneo noroccidental donde en el siglo siguiente hizo su aparición ese nuevo sistema médico basado en la institución universitaria. No sólo eso: sus monarcas pudieron conocer de cerca ese proceso, y ser partícipes activos de él, al contar entre sus dominios a la ciudad universitaria de Montpellier y al dirigir una de sus principales líneas de expansión política y militar hacia Italia. Las consecuencias culturales fueron evidentes, pero todavía insuficientemente estudiadas.

La medicalización de la sociedad catalanoaragonesa a partir de finales del siglo XIII fue profunda, y en absoluto limitada a las áreas urbanas. Gracias a los ricos fondos documentales conservados, los estudios realizados han demostrado desde la extensa presencia de médicos universitarios y de médicos extrauniversitarios sometidos a un perseverante control social mediante exámenes y licencias, hasta la difusión de políticas comprometidas con la salud y con ese nuevo modelo de medicina y de médico. La coexistencia entre el sistema universitario y el sistema "abierto", extrauniversitario, de formación médica, es característica del período. Como en el resto del Occidente latino, en la Corona de Aragón ese sistema "abierto" era mayoritario, pero sometido aquí a una presión combinada -institucional, legislativa y social- muy destacada.

Esa misma dicotomía se ve reflejada en los perfiles de las dos principales figuras intelectuales catalanas del momento: por un lado, Arnau de Vilanova, médico de papas y de reyes, amigo personal del rey de Aragón y verdadera alma de la universidad de Montpellier en esos cruciales años ${ }^{4}$; por el otro, Ramon Llull, el gran iluminado mallorquín, ferviente autor de un proyecto personal único en su tiempo cuyo objetivo profundo era, nada menos, ofrecer un nuevo método del acceso al conocimiento, alternativo y pretendidamente más asequible y mecánico que el aristotélico ${ }^{5}$. El primero,

institucions, sabers, pràctiques, protagonistes, en P. Gabriel (ed.), Història de la cultura catalana, vol. 1 (L'esplendor medieval, ss. XI-XV), Barcelona, Edicions 62, 1998, p. 247-270.

${ }^{4} \mathrm{La}$ obra completa de Arnau está en curso de edición, tanto la médica $(\mathrm{AVOMO}=$ Arnaldi de Villanova Opera Medica Omnia, Universitat de Barcelona-Fundació Noguera, fundada por Le de Villanova Opera Theologica Omnia. Institut d'Estudis Catalans-Facultat de Teologia de Catalunya-Scuoola Superiore di Studi Medievali e Francescani, dir. J. PERARNAU). La colección traducciones y de originales en catalán de algunas de sus obras. Para un estado de la cuestión sobre Vilanova, se consultarán las dos Trobades internacionals d'estudis sobre Arnau de Vilanova organizadas por J. PERARNAU y publicadas en "Arxiu de Textos Catalans Antics", 13 (1994) i 14 (1995) y 23/24 (2005), respectivamente, así como J. MENSA I VALLS y S. GIRALT I SOLER, Bibliografia arnaldiana (1994-2003), "Arxiu de Textos Catalans Antics", 22 (2003), 665734.

${ }^{5} \mathrm{La}$ obra completa de Llull está en curso de edición, tanto la latina $(\mathrm{ROL}=$ Raimundi Lulli Opera Latina, Corpus Christianorum) como la catalana (NEORL = Nova edició de les obres de Ramon Llull,'Patronat Ramon Llull, que complementan las viejas ORL = Obres Originals de Obres selectes de Ramon Llull (1232-1316), 2 vols., Palma de Mallorca, Moll, 1989, $2^{\mathrm{a}}$ ed. revisada, y del mismo autor, The Art and Logic of Ramon Llull: A User's Guide, Leiden, Brill, 2007. Puede consultarse también la Base de dades Ramon Llull-Llull DB $<$ http://orbita.bib.ub.es/llull > del Centre de Documentació Ramon Llull (CDRL), de la Universidad de Barcelona. Una presentación didáctica y multilingüe de Llull y su obra, elảborada 
paradigma de la ciencia oficial institucionalizada y de las élites intelectuales; el segundo, de la aparición en escena de nuevos sectores sociales, extrauniversitarios pero muy conscientes del valor personal, profesional y social del saber, del saber que emanaba de la institución universitaria.

Conviene que retengamos estos datos, porque nos serán útiles para comprender qué ocurre en los territorios de la Corona de Aragón con respecto a la elaboración y la difusión de saberes médicos, también los relativos al termalismo, durante los últimos siglos de la Edad Media.

En ese contexto social y cultural, presidido por una intensa difusión del nuevo sistema médico y por una medicalización profunda, contándose además con la tradición romana y árabe, la revalorización del baño, en general, y de las fuentes termales, en particular, fue muy temprana. En el plano general, el ejemplo árabe, todavía vivo en Valencia, fue determinante en el mantenimiento y en la creación de nuevos establecimientos públicos de baños a partir del siglo XIII. El aprovechamiento de los manantiales termales se benefició de la pervivencia de las creencias populares respecto a las virtudes salutíferas de las aguas calientes, con frecuencia revestidas de un halo de religiosidad, y esto hizo que muchos de aquellos continuaran en uso, a pesar de la ruina y el desmantelamiento de las instalaciones romanas. La difusión de la doctrina médica hipocraticogalénica, con su valoración de las acciones preventivas y terapéuticas del baño, reforzó ambos procesos, otorgándoles un aval de cientificidad que se demostró especialmente indestructible con los baños termales.

\subsection{Los baños termales catalanes}

En la Corona de Aragón, especialmente en Cataluña, la geología fue generosa con la existencia de manantiales termales, muchos de ellos conocidos y explotados desde la Antigüedad. Estas Aquae Calidae catalanas dieron origen a diversas poblaciones, fundadas alrededor de los antiguos establecimientos termales romanos, algunas de las cuales todavía hoy llevan el nombre de Caldes. Caldes d'Estrac (en la costa, al norte de Barcelona y muy cercana a ésta) y, sobre todo, Caldes de Montbui (al nordeste de Barcelona, con una de las aguas más cálidas del continente, $74^{\circ} \mathrm{C}$ ) fueron, por su proximidad a la capital, los "banys" termales catalanes más utilizados en la Edad Media. Caldes de Malavella (al sur de la ciudad de Gerona) o Caldes de Boí (en pleno Pirineo) constituyen otros ejemplos de Caldes, aunque de utilización más irregular en el período que aquí interesa. Otras localidades catalanas con "banys" termales de uso documentado durante la época medieval fueron la Garriga (muy cercano a Caldes de Montbui y por tanto no lejos de Barcelona), por el mismo CDRL, en Qui és Ramon Llull? < http://quisestlullus.narpan.net>. Para Llull y Barcelona, Quaderns Crema, 1999; y L. BADIA, La ciència a l'obra de Ramon Llull, en J. VERNET I GINÉS Y R. PARÉS I FARRÀS (dịrs.), La ciència en la història dels Pä̈sos Catalans, vọl. 1 (Dels àrabs al Renaixement), Valencia, Institut d'Estudis Catalans-Universitat de València, 2004, p. 403-442. 
Arles y el Voló (éstos últimos en el área de influencia de la segunda capital catalana, Perpiñán).

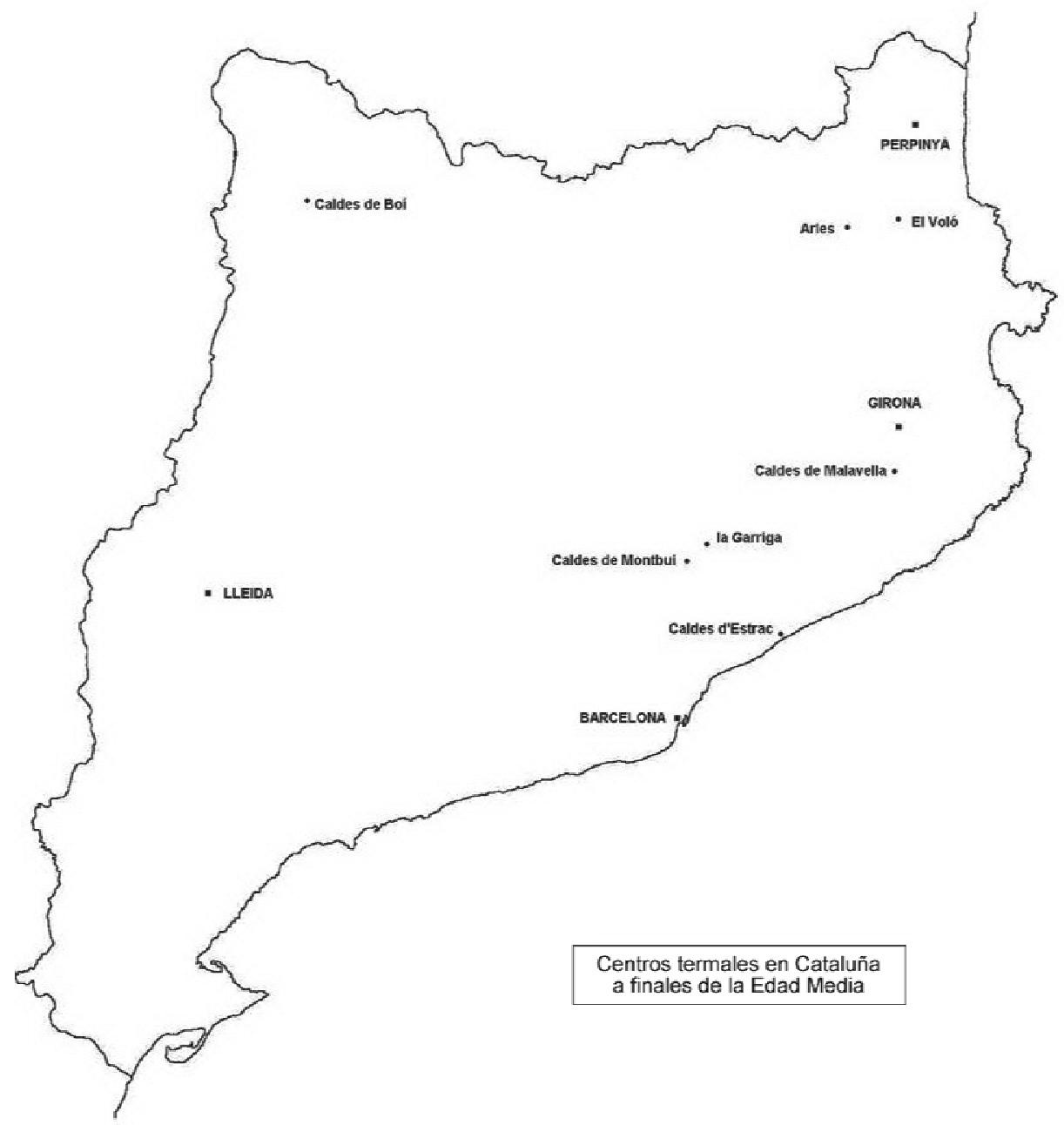


Los establecimientos balnearios en estas localidades, todas ellas pequeñas y situadas fuera, incluso lejos, de las principales áreas urbanas, no eran homogéneos. Los de Caldes de Montbui ya desde la Antigüedad eran los más utilizados y de las extensas termas romanas sobrevivían partes considerables. En este caso, los bañistas, que acudían de las zonas próximas y sobre todo de Barcelona, tenían opción a tres tipos de establecimientos, que reflejan una estratificación social clara: 1) las casas de baños, antecedentes de los actuales balnearios, que eran propiedad de individuos privados, en las que se hospedaban y bañaban los miembros de la élite social, y que estaban construidas sobre partes de las antiguas termas o en sus inmediaciones; 2) las piscinas públicas y seguramente mixtas, que ocupaban el centro de la plaza, en las que se podían bañar por un módico precio (administrado por el municipio) los visitantes y el pueblo en general que no deseara o no pudiera contratar los servicios de las primeras, y que aprovechaban las piscinas de las termas romanas; y 3) el hospital de pobres, regentado también por el municipio, en el que se acogían los visitantes o lugareños de menor capacidad económica, estuvieran o no enfermos, y que aprovechaba también un sector de las antiguas termas ${ }^{6}$.

Esta estructura parece que es la más completa que existió en la Cataluña medieval. Existieron hospitales semejantes al de Caldes de Montbui - del que se conservan los libros de administración del siglo XIV- en la cercana la Garriga (fundado en 1347), en Caldes de Boí, en Caldes d'Estrac y en Arles. Algunos de estos manantiales pasaron, durante la Edad Media, bajo control eclesiástico, siendo integrados en monasterios y santuarios construidos sobre las instalaciones romanas (mucho más modestas que las de Caldes de Montbui). Es el caso de Caldes de Boí o de Arles. En otros contados casos, como en la Garriga, también se documentan casas de baños privadas. En otros, finalmente, los antiguos baños romanos fueron propiedad y concesión del rey: así sucedía en Caldes d'Estrac.

Esta diversidad de establecimientos, de diferentes características, refleja las propias idas y venidas de la historia del termalismo. De las más o menos grandes instalaciones lúdicas romanas, cuyas aguas termales, médicamente valoradas, estaban revestidas ya de un halo de religiosidad, se pasó a una cristianización del poder salutífero de éstas, desprovisto de cualquier connotación lúdica. La nueva medicina que emanó de la institución universitaria bajomedieval favoreció el mantenimiento de esas instalaciones y el aprovechamiento de las aguas como negocio privado, a la vez que la caridad cristiana añadía hospitales para los más desfavorecidos.

La prescripción médica del baño en general y la valoración especial del baño termal favoreció su democratización y su difusión en todas las capas de la sociedad. Tanto los médicos como los reyes y los miembros de la nobleza laica y eclesiástica o de la burguesía emergente coincidieron en

${ }^{6} \mathrm{Ll}$. Cifuentes I Comamala, Els banys de Caldes de Montbui, de l'època medieval a la Il lustració, en Història termal de Caldes de Montbui, Caldes de Montbui, Ajuntament de Caldes de Montbui, 2001, p. 47-98. 
aceptar el valor terapéutico de los baños termales para determinadas enfermedades ${ }^{7}$. Para afecciones dermatológicas (como aconsejó Arnau de Vilanova a Carlos II de Nápoles en 1308), para la recuperación de los guerreros enfermos o heridos en la batalla (como se pronosticó a algunos caballeros heridos durante la conquista catalana de Cerdeña, en 1323-1324) o para el trataminento de otras enfermedades que, como en el caso anterior, podía comportar la exención de determinadas obligaciones para poder tomar los baños (como ocurrió con uno de los representantes del municipio de Lérida durante las cortes de Barcelona de 1340).

En la cúspide de la pirámide social, los reyes fueron muy sensibles al poder terapéutico del agua termal. No solo acudieron con regularidad a los balnearios, sino que dictaron medidas para mantener la limpieza de las aguas (como hizo Juan I con las de Caldes de Estrac en 1394, de titularidad real). Disponemos de algunos testimonios explícitos y detallados de algunos de estos monarcas de los siglos XIV y XV en los que reconocen, haciendo uso de la terminología médica, los beneficios del termalismo.

Las creencias tradicionales, el favor de la prestigiosa medicina universitaria y la asistencia de reyes y otras personas de rango, comportaron una gran afluencia a los lugares con aguas termales. El agua se convirtió, por tanto, en un factor de riqueza, y no sólo para los propietarios de casas de baños. La construcción de sólidas murallas, como en Caldes de Montbui o en Arles, resulta muy significativa.

Los monarcas difundían esta valoración médica y social de los baños termales en su círculo inmediato, autorizando desplazamientos de sus cortesanos y familiares (como hizo Alfonso el Magnánimo en diversas ocasiones) pero incluso de sus servidores, que podían eximir de sus obligaciones mientras seguían la cura (como hizo Juan I en 1394 con un criado de su cámara, enviado a los baños de Arles). El príncipe también podía intervenir ante las órdenes religiosas para que permitieran el acceso a los baños a monjas de clausura, sin olvidar de apelar al consejo de los médicos (como hizo Juan en 1377 con unas religiosas de Perpiñán que debían acudir a Arles).

Eran lugares en los que se había recuperado el sentido de lo lúdico. Lugares de encuentro social, pero también sexual. La documentación conservada no siempre nos explicita la primera de estas funciones, pero los testimonios sobre la segunda son muy numerosos, tanto por lo que se refiere a los baños fríos como a los calientes. Por supuesto, esta última función es la que atraerá la atención de los moralistas y de los autores literarios. El ámbito geográfico y cultural catalán no fue una excepción en estos procesos.

\subsection{Tratados médicos sobre los baños}

La doctrina médica hipocraticogalénica integró el baño con naturalidad en sus esquemas, poniendo el acento en sus acciones evacuantes y en su

\footnotetext{
${ }^{7}$ Para los casos que se citan a contịnuación en este apartado, entre otros, véase CIFUENTES, Els banys de Caldes de Montbui, que incluye un apéndice documental.
} 
uso preventivo y terapéutico. Estos conocimientos se transmitieron en diversas obras, entre las que destacan por su sistematicidad las grandes sumas que, procedentes del mundo árabe, llegaron a la Europa latina a partir del siglo XI, como el Pantegni de Alí Abbás o el Canon de Avicena. Otra vía de difusión, ésta con mayor capacidad de penetración social, fue la representada por los regimina sanitatis. En estos textos, que podemos calificar de divulgación médica, el uso preventivo del baño quedaba claramente integrado en las célebres res non naturales, y así fue asumido por un espectro social cada vez más amplio ${ }^{8}$.

La difusión de estos textos y de los conocimientos que vehiculaban facilitó el surgimiento de una demanda específica de tratados sobre baños, más concretamente sobre baños termales. Uno de los primeros y más destacados exponentes de este nuevo género literario médico, que se ha denominado de balneis, fue el poema de Pietro da Eboli sobre la localización y las virtudes de los afamados baños termales de la zona de Pozzuoli y Baias, cerca de Nápoles (Nomina et virtutes balneorum Putteoli et Baiarum), escrito a finales del siglo XII o principios del XIII. Textos como éste circularon entre los médicos y entre los no médicos, en ocasiones traducidos a las lenguas vernáculas y con ostentosas miniaturas que suelen delatar una clientela adinerada y extrauniversitaria y que constituyen documentos únicos sobre el uso de los baños termales en la Europa latina durante la Baja Edad Media 9 .

El género de balneis se desarrolló, durante los últimos siglos medievales, en Italia, bien alrededor de los centros universitarios (como es el caso de Gentile da Foligno), bien en el marco de las grandes cortes principescas (caso de Savonarola). La existencia de estos centros de enseñanza y elaboración doctrinal así como de unas élites con una sólida potencia económica y política se sumaba a una geología favorable intensamente aprovechada desde la Antigüedad romana y a una sociedad muy medicalizada.

${ }^{8}$ Véase, en particular, el de ARNAU DE VILANOVA, Regimen sanitatis ad regem Aragonum, ed. de L. GARCIA BALLESTER y M. R. MCVAUGH, estudio introductorio de P. GIL SOTRES con Omnia, vol. 10-I, Barcelona, Universitat de Barcelona-Fundació Noguera, 1996, edición que incorpora un extenso estudio del género; y el estudio de M. NICOUD, Les régimes de santé au siècle), 2 vols., Roma, Ecole française de Rome, 2007. La difusión del género incluyó también el uso de formatos tan decididamente divulgativos como el de los problemas: véase GIROLAMO MANFREDI, Quesits o perquens (regiment de sanitat i tractat de fisiognomonia), ed. de A. CARRÉ, Barcelona, Barcino (Els Nostres Clàssics, B25), 2004.

${ }^{9}$ Petrus DE EBOLO, Nomina et virtutes balneorum Putheoli et Baiarum; et Tabula super balneis Puteoli [atr. a Arnau de Vilanova], facsímil, introducción, ed. y trad. esp. e ingl. de L. GARCIA BALLESTER, 2 vols., Valencia, Universitat de València, 1997. Véase también el estudio de L. GARCíA BALLESTER, Śobre el origen de los tratados de baños ('de balneis') como género literario en la medicina medieval, "Cronos" 1 (1998), p. 7-50; S. MADDALO, Il De balneis puteolanis di Pietro da Eboli: realtà e simbolo nella tradizione figurata, Ciudad del Vaticano, Biblioteca Apostolica Vaticana, 2003. La más completa recopilación de textos medievales del género fue publicada por K. GESSNER, De balneis omnia quae extant apud Graecos, Latinos, et Arabas, tam medicos quam quoscunque ceterarum artium probatos scriptores qui vel integris libris, vel quoquo alio modo hanc materiam tractaverunt... in quo aquarum ac thermarum omnium, quae in toto fere orbe terrarum sunt, metallorum item, et reliquorum mineralium naturae, vires, atque usus exquisitissime explicantur, indicibus quator appositis, Venecia, herederos de Lucantonio Giunta, 1553 [véase un ejemplar digitalizado en la Biblioteca Digital Dioscórides de la Biblioteça de la Universidad Complutense de Madrid: http://cisne.sim.ucm.es/search*spi S4]. 
Sin duda, el resto del Occidente latino no disponía de las mismas condiciones de partida y ello puede contribuir a explicar porqué fuera de Italia el género se desarrolló con un considerable retraso, incluso de siglos ${ }^{10}$.

Estos factores podrían bastar para explicar porqué en tierras catalanas no se dio producción alguna sobre este tema hasta la época moderna. Sin embargo, las razones de este vacío parecen algo más complejas. Se ha destacado con frecuencia que una de las características definitorias de la producción médica en la antigua Corona de Aragón es su extrema exigüidad (dejando aparte el caso literalmente extraordinario de Arnau de Vilanova). Esta escasa y poco relevante tratadística médica se ha relacionado tradicionalmente sólo con la debilidad de la institución universitaria durante el período bajomedieval: Montpellier, señorío de los reyes de Aragón y de Mallorca hasta 1349, podía dejar sentir su influencia en otros ámbitos pero era una realidad demasiado lejana como para dinamizar la producción escrita "nacional"; y Lérida, fundada en 1300 y de inicios vacilantes hasta la segunda mitad del siglo XIV, tuvo efectivamente la única facultad de medicina en la Corona de Aragón hasta el siglo XVI. El peso de este factor, la debilidad de la institución universitaria propia, parece evidente, pero ¿basta para explicar ese virtual desierto en la producción escrita? Creemos que no, y que deben buscarse, además, otras causas en la estructura y en las actitudes sociales hacia la medicina y los médicos y hacia el mundo de la salud en general. Los estudios recientes, a los que ya hemos aludido, permiten afinar en este análisis y proponer lo que, de momento, es solo una hipótesis.

Siempre con respecto a la medicina y la salud, esa "debilidad de la institución universitaria" catalanoaragonesa - e ibérica, en general- tenía sus raíces profundas en la extraordinaria vitalidad de los sectores extrauniversitarios, del llamado "sistema abierto" de formación en todos los oficios, también en los correspondientes a este ámbito. Aunque la presencia de médicos con "grados" universitarios se documenta en todo el territorio, los formados mediante contratos de aprendizaje privados ("afermament") fueron muy mayoritarios durante todo el periodo. Estos médicos extrauniversitarios, parapetados en poderosos gremios, lucharon por mantener el autocontrol del propio oficio contra el intervencionismo de la institución universitaria, de los municipios y de la monarquía, pero se sometieron a un control social riguroso mediante exámenes y licencias para ejercer que garantizaban, en última instancia, su integración en el modelo universitario. El prestigio social de este modelo explica que, a pesar de su humilde formación, su objetivo no fuera

\footnotetext{
${ }^{10}$ Una síntesis en M. NICOUD, Les médecins italiens et le bain thermal à la fin du Moyen Âge, "Medievales: Langue, textes, histoire", 43 [=Le bain: espaces et pratiques] (2002), 13-40. Sobre el aprovechamiento de las fuentes termales italianas y sobre la literatura que originaron, véase $\mathrm{D}$. BoISSEUIL, Le thermalisme en Toscane, à la fin du Moyen Age: les bains siennols de la fin du XIII siècle au début du XVI siẹcle, Roma, Ecole française de Rome, 2002; M. GUÉRIN-BEAUVOIS y J.-M. MARTIN (eds.), Bains curatifs' et bains hygléniques en Italie de l'Antiquité au Moyen Age, Roma, Ecole française de Rome, 2007; y P. ANDRIOLI NEMOLA, O. S. CASALE y P. VITI (ed.), Gli umanisti e le terme: atti del convegno internazionale di studio (Lecce-Santa Cesarea Terme, 23-25 maggio 2002), Lecce, Conte, 2004. Para el contexto ibérico, véase GIRÓN IRUESTE, Uso médico dêl agua en el mundo hispánico.
} 
otro que esa integración, se consiguiera ésta en la misma generación o en la siguiente.

Al margen de la producción original sobre el género, la gran vitalidad de la literatura médica en catalán durante los siglos XIII al XVI está en directa relación con la potencia de esos sectores extrauniversitarios pero sobre todo con su designio de integración en un modelo que les aportaba un mayor prestigio profesional y social. Aunque no faltan las obras originales (con frecuencia de carácter compilatorio), se trata de una literatura médica constituida fundamentalmente por traducciones. Pero no traducciones cualesquiera: el carácter de las traducciones en circulación delata ese deseo de integración en el modelo universitario. Entre éstas, se cuentan no sólo todos los manuales prácticos más usuales, sino también textos como la Isagoge de Johannitius, el De ingenio sanitatis de Galeno o el Canon de Avicena, así como comentarios a alguna de estas obras. Traducciones, por tanto, pensadas en función de una estrategia determinada, que apuntaba hacia el modelo universitario $^{11}$.

Se trata, por tanto, de una sociedad condicionada a recibir y a utilizar, en latín y en vulgar, obras científicas de probado prestigio y efectividad más que a producir textos originales - con tantas excepciones como se quiera, repetimos. La medicalización intensa, asumida por todos los estamentos sociales, en una sociedad cuya burguesía, nobleza y monarquía, aunque activas, no disponían de una potencia económica comparable a la de otras áreas del Occidente latino, no hacía más que ampliar esa tendencia a la recepción más que a la producción.

No parece extraño que esa sociedad fuera la que dio origen al fenómeno Llull y al lulismo: una propuesta de un nuevo método más accesible a los extrauniversitarios, pero - no lo olvidemos - cuyo objetivo último no era otro que ser aceptado por los universitarios que, naturalmente, jamás lo entendieron.

Parece probable que por todo ello, en ese territorio receptor pero no productor de literatura médica, aunque sí con una medicalización profunda, con unas élites comprometidas, con innovaciones en el ámbito medicosocial incluso muy precoces, con baños termales utilizados y médicamente valorados, no se viera la necesidad de realizar aportaciones al género de balneis durante los siglos medievales. Además, la posible existencia, muy dificil de documentar, de una cultura terapéutica tradicional en la que los baños termales tenían un papel reconocido podría haber contribuido al desinterés de los médicos por desarrollar una tratadística especializada sobre el particular.

${ }^{11}$ Ll. CifUENTES I COMAMALA, La ciència en català a l'Edat Mitjana i el Renaixement, Barcelona-Palma, Universitat de Barcelona-Universitat de les Illes Balears, 2002 [2 $2^{\mathrm{a}}$ ed. revisada y ampliada: 2006]. 


\section{DIFUSIÓN SOCIAL Y REFLEJO LITERARIO}

La literatura de creación constituye un magnífico observatorio de la difusión de procesos y fenómenos de todo tipo en una sociedad determinada. Sin embargo, no siempre se tiene en cuenta que, como ocurre con la documentación jurídico-administrativa, producida para unos fines específicos -que no incluían el apoyo a los estudios históricos del futuro-, la creación literaria no proporciona un reflejo neutral y aséptico de las realidades de su tiempo. Se trata de un testimonio concreto, con frecuencia muy rico, pero uno más entre otros y muchas veces vehículo de determinados intereses o puntos de vista; un material sensible que debe saberse utilizar con precaución.

Subrayamos este punto, aunque puede parecer evidente, porque el reflejo literario de la cultura del baño durante la Baja Edad Media no fue en absoluto un reflejo fotográfico, sino una visión concreta, sesgada incluso, de esa realidad. Una cata en los textos literarios catalanes de los siglos XIV y XV nos permite reconocer el arraigo social de su práctica, su medicalización y, de forma muy insistente, el ataque de los moralistas para quienes, siendo el baño ocasión para las reuniones sociales más distendidas, podía dar lugar a los más graves desórdenes morales. Sin embargo, en todos los casos son referencias a baños de agua fría. Se nos plantean, por tanto, dos interrogantes.

La primera pregunta es: ¿por qué en una sociedad en la que el uso de los baños termales no era nada extraño no se transmite ese uso en su producción literaria? Aparentemente, hay que buscar la respuesta en el carácter y en la intencionalidad de esa producción literaria. Se trata, en efecto, de producciones originadas en un ámbito urbano, cuyo enfoque de este tema se centra en las frecuentadas instalaciones urbanas, y cuya intención última no deja de ser moralizadora. Por ello poco importa que estemos hablando de autores con un entorno familiar médico o siendo ellos mismos médicos universitarios.

Segunda pregunta: ¿este tratamiento literario del baño hace realmente referencia tan sólo a los baños de agua fría o debe interpretarse como una referencia genérica a la cultura del baño? Nos inclinamos por pensar que se trata de una referencia genérica, que no pretende discriminar entre baños de agua fría y baños de agua caliente (ambos perfectamente asumidos por el galenismo), sino que la diferenciación que se sugiere, en todo caso, va por otros caminos. Son los baños comunes, sobre todo si son mixtos, los que atraen las condenas morales... y los que proporcionan tema literario. Tanto los baños fríos como los calientes podían ser comunes y mixtos, pero eran los primeros, baños urbanos, los más evidentes, los más visibles, los más multitudinarios, y sí, también los que tenían una cohartada terapéutica -que no preventiva- más débil. 


\subsection{Reflejo literario de la cultura del baño en el contexto románico}

La mitología nos ofrece ejemplos de baños que proporcionan una conservación extrema de la salud a la persona que se sumerge en ellos. Baste pensar en el caso de Aquiles o de Sigfrido, que ven sus cuerpos protegidos -excepto el talón y el hombro- para siempre por haber sido introducidos de pequeños en unas aguas virtuosas. En su sentido positivo, los baños significan la salvación física del individuo; salvación que el bautismo elevará al plano espiritual en el mundo cristiano.

La literatura francesa medieval nos ofrece un ejemplo semejante en el Livre de Mélusine que Jean d'Arras escribió para el duque Jean de Berry entre el 1387 y el $1392^{12}$. Es un relato de orígenes folclóricos que difunde una de las leyendas más atractivas de la Edad Media: la historia de un hada que se convierte en mujer por amor y que acaba condenada a vivir en forma de serpiente con alas porque su marido humano incumple una promesa. La infracción que comete Raymondin, el esposo, es observar qué hace todos los sábados Melusina -que en la ficción pertenece al linaje de los Lusignan, reyes de Chipre, Armenia y Jerusalén. Lo que ve, y no debería haber visto, es que su mujer, que del ombligo para abajo tenía forma de cola de serpiente, se baña en una gran cuba de mármol con escalones. El baño la protege y le permite recuperar de nuevo, cada semana, la forma humana. Tanto Aquiles como Sigfrido y Melusina acaban mal. Y es que el baño no siempre salva: a veces, incluso tiene consecuencias muy perniciosas.

En efecto, en la Europa latina medieval circulaba una anécdota, que Averroes había citado en su Colliget, según la cual una mujer que frecuentaba los baños había quedado embarazada después de sumergirse en el agua, sin contacto previo con hombre alguno. La historia, utilizada en el debate sobre la espermatogénesis a favor de la postura de Aristóteles, que defendía que el embarazo era posible sin emisión de semen y sin placer femenino ${ }^{13}$, fue utilizada por moralistas y por autores literarios para evidenciar que los baños eran lugar propicio para entregarse a los juegos más libidinosos y, por tanto, dignos de censura a pesar de sus buenos efectos para la salud ${ }^{14}$.

Efectivamente, la literatura románica de la Edad Media nos ofrece ejemplos de esta doble interpretación de los baños. Si por un lado, la literatura recoge el carácter preventivo del baño, por otro censura su relación directa

\footnotetext{
${ }^{12}$ JEAN D'ARRAS, Melusine ou la noble histoire de Lusignan: roman du XIV’̀ siecle, ed., trad., presentación y notas de J.-J. VINCENSINI, París, Librairie Générale Française, 2003.

${ }^{13}$ D. JACQUART y C. THOMASSET, Sexualité et savoir medical au Moyen Âge, París, Presses Universitaires de France, 1985.

${ }^{14}$ Para el ámbito cultural catalán, véase FRANCESC EIXIMENIS, Terç del Crestià, cap. 32 (en FRANCESC EIXIMENIS, Terc del Cristià, ed. de M. DE BARCELONA, N D'ORDAL y F. DE TARRAGONA, 3 vols., Barcelona, Barcino [Els Nostres Clàssics, B 1-2 y 4], 1929-1932); y JAUME ROIG, Espill, versos 8646-8657' (en JAUME ROIG, Espill, ed., trad. y comentarios de A. CARRÉ, Barcelona, Quaderns , Crema, 2006, p. 352-354; véase también A. CARRE, La medicina com a rerefons cultural a l'Espill de Jaume Roig, en A. CARRE y J. SOLERVICENS, Jaume Roig $i$ Cristôfor Despuig: Dos assaigs sobre cultura i literatura dels segles XV $i$ XVI, Vic, Eumo, 1996, p. 7-71, esp. las p. 41-42).
} 
con el sexo. La asociación entre casas de baños y burdeles, ampliamente documentada en la Europa latina, facilitó que la visita a los baños fuera moralmente condenable y así lo hicieron textos como los penitenciales y autores como los predicadores o los moralistas ${ }^{15}$.

Las fuentes clásicas, pronto traducidas a las lenguas vernáculas, ofrecen ejemplos respetados, imitados y copiados. Para darnos cuenta de ello, basta leer las Sátiras de Juvenal, un texto estudiado en las escuelas de gramática y en las facultades de artes que, significativamente, constituyó un rico filón para el debate que, sobre la condición femenina, se estableció en la literatura desde el siglo XIII ${ }^{16}$. Según este autor romano, los vicios principales de las mujeres, que desaconsejan el matrimonio, son, entre otros, que cometen adulterio, que dilapidan los bienes, que son marisabidillas y crueles, que abusan de las joyas y los afeites... y que van con frecuencia a los baños. Otro autor latino, Valerio Máximo, explicita claramente, en sus tan difundidos Factorum et dictorum memorabilium, la vinculación del baño con la lujuria: cuando expone que Cayo Sergio Orata fue el primero que fundó baños en la ciudad de Roma ${ }^{17}$ lo hace al principio del título primero del libro noveno, dedicado precisamente a la lujuria y al deseo carnal.

Entre las obras literarias románicas con una notable presencia del tema del baño destaca Flamenca, la bella novela occitana escrita a finales del siglo XIII y ambientada en el norte de Auvernia, una zona rica en aguas termales ${ }^{18}$. A diferencia de las obras que acabamos de comentar y de las catalanas, que comentaremos a continuación, se trata esta vez, excepcionalmente, de una referencia concreta a baños termales. Esta es la única diferencia porque, tal como hemos expuesto, podemos comprobar que el tratamiento literario de los baños calientes y de los baños fríos es el mismo: un tratamiento que combina salud y corrupción. Flamenca, la protagonista, está casada con el celoso Archimbaut de Borbón, que la mantiene encerrada en una torre y sólo le permite salir para acercarse a aquellos dos sitios que le van a permitir mantener la salud tanto de su cuerpo como de su alma: los baños y la iglesia. Cuando aparece en escena Guilhem de Nevers, con su dominio de la caballería y de la pluma, se perfila como el amante perfecto. Seducirá a la dama en la

${ }^{15}$ J. RosșaUd, La prostituzione nel Medioevo, Rome-Bari, Laterza, 1984 [trad. esp.: Barcelona, Ariel, 1986].

${ }^{16} \mathrm{~A}$ propósito del debate pro y antifeminista en la literatura, véase, por ejemplo, Ma $\mathrm{J}$. LACARRA, Algunos datos para la historia de la misoginia en la Edad Media, en Studia in honorem prof. Martí de Riquer, Barcelona, Quaderns Crema, 1986, p. 339-362; A. BLAMIRES (ed.), Woman Defamed and Woman Defended: An Anthology of Medieval Texts, Oxford, Clarendon Press, 1992; y R. CANTAVELLA, Els cards i el llir: una lectura de l'Espill de Jaume Roig, Barcelona, Quaderns Crema, 1992.

${ }^{17}$ «Gayo Sergio Orata va ser lo primer qui trobà e ordenà banys artificials en la ciutat de Roma", según la traducción catalana comentada de Antoni Canals, llevada a cabo en 1395, en el mismómbito cronológico y cultural que aquí interesa (véase VALERIO MÁXIMO, Llibre anomenat. Valeri Maximo dels dits y fets memorables: traducció catalana del segle XIV per frare Antoni Canals, ed. de R. MIQUEL I PLANAS, 2 vols., Barcelona, Biblioteca Catalana, 1914, en vol. 2, p. 300).

${ }^{18}$ Le roman de Flamenca, ed. de P. MEYER, París, E. Bouillon, 1901. 
iglesia y conseguirá una cita con ella en los baños, donde tendrá lugar el adulterio.

\subsection{Los baños en la literatura catalana medieval}

La literatura catalana, predominante en la antigua Corona de Aragón, no es una excepción en cuanto al reflejo fiel de ese sistema de valores médico y moral. Pueden observarse, no obstante, algunas sutiles diferencias.

Las obras didácticas nos transmiten la visión eminentemente moral, pero sus autores no olvidan la importancia médica del baño, que intentan matizar. Así lo hace el franciscano Francesc Eiximenis, cuyas obras gozaron de una amplísima difusión, en el Dotzè de su Crestià (1385-1386), una enorme suma enciclopédica sobre el cristiano ideal. Eiximenis valora el uso preventivo y terapéutico del baño, pero insiste en los peligros que comporta su práctica indebida, tanto para la salud del cuerpo como para la del alma, con una clara alusión al pecado capital de la lujuria. Si Eiximenis reconoce que el baño es un placer honesto para los príncipes y sus hijos, que deben «lavar-se mans e peus e cara ab aygues plasens ${ }^{19}$, también afirma, citando la autoridad médica de Constantino el Africano, que una de las causas naturales que hacen al hombre flaco y cobarde es el abuso del baño ${ }^{20}$. Los baños públicos son lugar apto para los contactos sexuales. De ahí que, según él, las viudas disolutas los frecuenten tan a menudo ${ }^{21}$ y que las doncellas que deseen conservar su virginidad deban evitar acudir a ellos sin necesidad, pues son lugar donde tanto mujeres como hombres pierden fácilmente la castidad:

La doncella qui vol viure casta que sia axí matex abstinent e nodrida en menjar e en beure, car menjàs delicats e calts, e vi preciós e fort, ben jaure e estar en ociositat, molt dormir, e anar sens necessitat a banys e aver companyia de males persones, fan perdre la castedat a qualsevol doncella, he ha hom encara, per bo que sia! $!^{22}$

En el libro tercero de Lo somni (1398-1399), dedicado a la crítica de las mujeres, Bernat Metge, hijo de un boticario de Barcelona y secretario del rey, censura sin paliativos los baños públicos por ser, según él, lugar que incita al placer sexual. Las mujeres -dice en un pasaje en el que traduce a Boccaccio-, con la excusa de conservar la juventud van a los baños demasiado maquilladas, pero su objetivo real no es la higiene o la salud, sino la seducción:

${ }^{19}$ FrANCESC EIXIMENIS, Dotzè llibre del Crestià, ed. de C. WiTTLIn, X. RENEDO et al., 3 vols. publ. Gerona, Col-legi Universitari de Girona/Universitat de Girona-Diputació de Girona, 1986, 1987 y 2005, en vol. II.1, p. 206.

${ }^{20}$ Otras causas que aḍce están relạcionadas también con las seis cosas no naturales del galenismo, como los movimientos o accidentes del alma (la tristeza, el temor o la ira), la dieta (comer habas, guisantes, puerros, cebollas o ajos) y el dormir o el velar en demasía. Eiximenis también incluye entre las causas el estudiar demasiado o el pensar en exceso en algo concreto, entre otras (EIXIMENIS, Dotzè, vol. II.1, p. 243).

${ }^{21}$ EIXIMENIS, Dotzè, vol. II.2, p. 396.

${ }^{22}$ EIXIMENIS, Dotzè, vol. II.2, p. 404. 
Quantes solemnitats penses que sien servades quan deuen anar o van al bany, lo qual dien elles que continuen per conservar jovent? No te les poria dir, tantes són. Sàpies, però, breument, que untades hi van e pus untades se'n tornen ${ }^{23}$.

Los peligros para el hombre son evidentes y fatales, puesto que incluso pueden llegar a acabar con su vida. Metge lo afirma rotundamente con un tecnicismo médico, la humedad radical, que, como es sabido, designa a una constante vital paralela al calor natural y cuya pérdida acarrea la enfermedad y la muerte:

Los enemics del teu humit radical, los cuals acompanyen les fembres del bany al teu llit, són aquests: molts perfums e aigües, calç viva, olis, sabons $^{24}$.

Comprobamos como, tanto el moralista franciscano como el escribano barcelonés hijo de apotecario, coinciden en el uso de argumentos morales y médicos contra los baños públicos, una combinación que prefigura los ataques letales que recibirá la cultura del baño un siglo más tarde.

La novela Tirant lo Blanc, escrita por el noble valenciano Joanot Martorell (1460-1464), nos aporta otra perspectiva distinta del baño, que parece explicarse por la extracción social del autor, el carácter de la novela - que presenta una visión lúdica del amor y la sexualidad- y el tipo de baño que refiere (un baño en una casa o palacio). En efecto, el célebre episodio del baño de la princesa Carmesina (cap. 231) introduce una escena voyeurística que recuerda a otra semejante narrada en el Filocolo de Boccaccio ${ }^{25}$. En esta escena se plantea una visión jocosa, festiva y vitalista del baño que se aleja de las pulsiones de moralistas y misóginos, en la cual documentamos también la transmisión de algunos interesantes aspectos del saber médico sobre la alimentación relacionada con el baño. Después del baño, Carmesina toma como colación «un parell de perdius ab malvesia de Candia e aprés una dotzena d'ous ab sucre e ab canyella. Aprés se posà en lo llit per dormir ${ }^{26}$. Martorell sabía - y el público de la novela también- que, según los médicos,

\footnotetext{
${ }^{23}$ El fragmento es una traducción del Corbaccio de Boccaccio (véase BERNAT METGE, Lo somni, ed. y comentarios de L. BADIA, Barcelona, Quaderns Crema, 1999, p. 131).

${ }^{24}$ MetGe, Lo somni, p. 131.

${ }^{25}$ En el capítulo 111 del libro cuarto, Glọicia eșconde a Floris en una habitación contigua para que pueda ver las danzas de Blancaflor sin ser visto. Después, lo introducirá en la cama de la donzella, como hará también Plaerdemavida con Tirant (en GIOVANNI BOCCACCIO, Filocolo, ed. de M. MARTI, Milán, Rizzoli Editore, 1969, p. 592-594). En el famoso episodio de las cuestiones de amor del mismo libro cuarto (entre los capítulos 17 y 72), el baño aromático preparado por un prudente caballero enamorado, sirve para devolver la vida a su amada, que falleció en el momento del parto y que ya había sido sepultada: «fẹce un solenne bagno apparecchiare, nel quale molte virtuose erbe fece mettere; e, appresso, lei vi mise, faccendola in quella maniera che si convenia servire teneramente e governare. Nel qual bagno poi che la donna fu per alquanto spazio dimorata, il sangue, dintorno al cuore congelato per lo ricevuto freddo, caldo per le freḍde vene si cominciò a spandere, e gli spiriti tramortiti cominciarono a ritornare nelli loro luoghi» (BOCCACCIO, Filocolo, p. 538). 699.

${ }^{26}$ JoAnot Martorell, Tirant lo Blanc, ed. de M. DE RIQUer, Barcelona, Ariel, 1979, p.
} 
ciertos alimentos estimulan el deseo del coito mientras que otros lo reprimen. Así, por ejemplo, en el divulgadísimo Lilium medicine de Bernardo de Gordon se citan entre los alimentos que estimulan el coito precisamente las gallinas, perdices y faisanes, los huevos blandos para sorber y el vino dulce ${ }^{27}$.

Pero en la literatura catalana la obra "estrella" por lo que respecta a las alusiones a la cultura del baño es, sin duda, el Espill (1460) de Jaume Roig, una larga diatriba en verso contra las mujeres en la que el protagonistanarrador nos cuenta sus desgraciados matrimonios ${ }^{28}$. Muy probablemente, el oficio del autor, un reconocido médico universitario de la ciudad de Valencia, tiene mucho que ver en ello y anuncia ya el cambio de actitud de los médicos hacia el baño. Roig plantea las diferentes visiones que la medicina y la moral tenían de los baños públicos y así recoge tanto su función terapéutica como su relación con la sexualidad y el vicio. En el libro segundo, el protagonistanarrador critica a su segunda esposa, la viuda, mujer de mal carácter que tomó toda clase de medicamentos y pócimas para quedarse embarazada, aunque sin éxito. Al final, enfermó tanto que tuvo que interponerse el protagonistanarrador para salvarla de la muerte ${ }^{29}$ :

$$
\begin{aligned}
& \text { L'ànima ab cos } \\
& \text { - cert dir-te gos -, } \\
& \text { o abjurada } \\
& \text { o crec damnada, } \\
& \text { que fora morta } \\
& \text { sinó que en l'Horta, } \\
& \text { a l'alqueria } \\
& \text { que jo hi tenia, } \\
& \text { la fiu portar. } \\
& \text { Fiu-la-hi restar } \\
& \text { per més d'un any: }
\end{aligned}
$$

\author{
havia-hi bany \\ e molts deports. \\ $\mathrm{Ab}$ bons conforts \\ e valent metge, \\ son mal de fetge \\ e batiments, \\ esmortiments \\ e la flaquea, \\ sinó bravea, \\ tot l'àls curà!
}

Entra en escena, pues, la medicina universitaria y el médico competente en ella actúa sobre tres de las seis cosas no naturales del galenismo: sobre el aire que nos rodea, al recomendar un cambio de escenario y pasar una temporada en el campo; sobre las repleciones y evacuaciones del cuerpo, al recomendar la práctica del baño; y sobre los accidentes del alma, al recomendar que la esposa se distraiga. Se consigue así curarla de sus enfermedades físicas... pero no de las morales.

\footnotetext{
${ }^{27}$ Véase, por ejemplo, en BERNARDO DE GORDONIO, Lilio de medicina: edición crítica de la versión espanola (Sevilla 1495), ed. de B. DUTTON y M ${ }^{\mathrm{a}}$ N. SÁNCHEZ, 2 vols., Madrid, Arco/Libros, 1993, en vol. 1, p. 303 . De la traducción catalana medieval de esta enciclopedia médica tan sólo se conservan algunos fragmentos del antidotario (véase CIFUENTES, La ciéncia en català, p. 94-95).

${ }^{28}$ Véase ROIG, Espill; y A. CARRÉ, El rescrit de Jaume Roig i les noves rimades comediades, en L. BADIA, M. CABRE y S. MARTí (ed.), Literatura i cultura a la Corona d'Aragó (s. XIII-XV): Actes del III Col loqui "Problemes i Metodes de Literatura Catalana Antiga" (Universitat de Girona, 5-8 de juliol de 2000), Barcelona, Curial-Publicacions de l'Abadia de Montserrat, p. 355372.

${ }^{29}$ RoIG, Espill, vs. 4645-4665, p. 224.
} 
De la primera esposa, la doncella, nos informa que frecuentaba demasiado los baños públicos en un pasaje con evidentes connotaciones eróticas en el que aparecen un boticario y una bañadora, profesionales habituales en los baños públicos de su época ${ }^{30}$ :

\author{
Sovint anava \\ de nit al nou \\ bany d'en Sanou, \\ o d'en Suau; \\ en lo palau \\ de despullar \\ vereu ballar, \\ en bells tapits, \\ aücs, salts, crits, \\ ab ses veïnes. \\ Perdius, gallines, \\ pollets petits, \\ juleps, solsits, \\ ous ab gingebre, \\ los durs ab pebre! \\ Grec e clarea \\ sense perea,
}

\author{
la malvasia \\ per cortesia \\ en gobellets. \\ Los artalets \\ no els hi preaven, \\ e sí hi empraven \\ pegats de llambre, \\ benjuí, ambre, \\ aigües, almesc. \\ Feia fer fresc \\ molt citronat, \\ carabassat, \\ prou gingebrons, \\ e canyellons, \\ fin tartugat \\ i caponat \\ en lletovari.
}

Las dos casas de baños citadas en el pasaje están bien documentadas en la ciudad de Valencia: los baños de Sanou se encontraban cerca de la parroquia de Sant Llorenç, según un documento de 1380, mientras que los de Suau, en servicio hasta mediados del siglo XX, eran conocidos como los baños del Almirall porque se hallaban situados en el palacio del mismo nombre, justo detrás de la catedral ${ }^{31}$. Como en el capítulo citado del Tirant lo Blanc, el catálogo de manjares, vinos y sustancias aromáticas se caracteriza por sus conocidas virtudes afrodisíacas: incluso Ramon Llull, en el capítulo 91 de su Doctrina pueril, expone que por olfatear ámbar y almizcle se engendra la lujuria $^{32}$. La penetración social de estos conocimientos la documentamos, por ejemplo, en la actuación de cierta prostituta siciliana de mediados del siglo XIV, que estimulaba a sus clientes con baños de estufa combinados con 'jarabes confortativos ${ }^{\prime 3}$.

\footnotetext{
${ }^{30}$ RoIG, Espill, vs. 2646-2679, p. 158-160.

${ }^{31} \mathrm{R}$. MiQUEL I PlanaS (ed.), Spill o Libre de consells de Jaume Roig, poema satíric del segle $X V, 2$ vols., Barcelona, Biblioteca Catalana, 1929-1950, en vol. 2, p. 295.

${ }^{32}$ Ramon Llull, Doctrina pueril, ed. de J. Santanach i Suñol, Palma, Patronat Ramon Llull (Nova Edició de les Obres de Ramon Lllull, 7), 2005, p. 252 [véase también: http://www.narpan.net/ben/indexdp.htm.

${ }^{33}$ «En Vallès sa gloriayava que jamay no sabé pler de fembra sinó d'equesta, car deya que a .III. ores la nit li feya bayns d'estuba e li donava a boura axarobs confortatius, axí que nit hi avia aguda que .X. vagades avia agut affer ab ela, axí que dins aquels .X. dies tot l'ach suclat e mamat e buydat, que com partim de Castel de Càler més semblava mort que viu... " (Ll. CIFUENTES I COMAMALA, "Una confidència feta al notari Bartomeu de Miramat per fra Francesc, bisbe de Bisarcio: 'fembres', febres i “desnaturament' a la Sardenya de mitjan segle XIV", Estudis Històrics $i$ Documents dels Arxius de Protocols, 17 [1999], 7-24, en las p. 23-24).
} 
Los tratados de medicina, sobre todo los de carácter ginecológico, explican cómo debe prepararse un baño terapéutico que, acompañado de una alimentación determinada y de la práctica sexual preceptiva, hará posible el embarazo, incluso en casos de esterilidad ${ }^{34}$. No es de extrañar, pues, que la esposa viuda del Espill, en sus intentos por quedarse embarazada, recurriera a médicas, a brujas, a comadronas, a adivinas, a boticarios y herbolarios, pero también a bañadoras ${ }^{35}$. En un largo discurso nocturno, el sabio Salomón pone el ejemplo de una malvada mujer médico que también usaba el baño para que sus pacientes concibieran ${ }^{36}$ :

\author{
A totes tres \\ en bany les mes, \\ medicinà \\ o metzinà; \\ may no pariren.
}

En este caso, el baño terapéutico no surte efecto porque, en el fondo, el médico de Valencia priorizaba la moral por encima de todo.

En el libro segundo, cuando el protagonista-narrador nos habla de su triste matrimonio con una joven novicia que había sido mal educada en el convento, cita el caso de una monja apóstata que defendía exacerbadamente el uso de la sexualidad apoyándose en el conocido versículo bíblico "creced y multiplicaos" (Gn 1,28). Según Roig, la monja en cuestión tenía una larga experiencia adquirida tras haber caminado por todo el mundo ${ }^{37}$ :

\author{
ha prou caçat, \\ lo món cercant \\ he traspassant \\ per Ceca i Meca, \\ la Vila-seca \\ e Vall d'Andorra, \\ Volta d'en Torra \\ e Santa Creu, \\ per tot arreu, \\ fins Pont Trencat.
}

\footnotetext{
${ }^{34}$ Así lo leemos, por ejemplo, en el Libro de amor de mujeres, una obra en hebreo posiblemente escrita no antes de mediados del siglo XIII en territorios de Cataluña o de Provenza. Según este texto, los sabios de Grecia escribieron esta receta: «toma huevos de cuervo y centeno, amásalos juntos y haz un pastel. Ella ha de tomar un baño: toma artemisa, poleo real y calamento, en partes iguales; ébolos, abrótano y romero, de cada uno cinco puñados; calamento, orégano, mentastro, marrubio, hierba violeta y rosa subálvida, de cada uno siete puñados. Cuécelos bien y que se bañe tres días [consecutivos]. A continuación que coma el pastel. Después, que copule y se quedará embarazada incluso aunque sea estéril; ha sido verificado y. experimentado». O esta otra: "Los sabios de Grecia hacen este remedio para la estéril; toma quince o veinte cabezas de corderos y cuécelas en una olla con agua, y con este agua que se bañe nueve días. Toma, después, lengua de cuervo y reduce a polvo, amasa con huevos de cuervos y haz un pastel. Que coma nueve días seguidos y se quedará embarazada sin duda; ha sido verificado y experimentado» (C. CABALLERO, ed., El libro de amor de mujeres, Granada, Universidad de Granada, 2003, p. 6667).

${ }^{35}$ RoIG, Espill, vs. 4522-4533, p. 220.

${ }^{36}$ RoIG, Espill, vs. 8825-8829, p. 358.

${ }^{37}$ RoIG, Espill, vs. 6128-6137, p. 272.
} 
Los topónimos del episodio tienen su interés. Recorrer "la Seca y la Meca y el Valle de Andorra" es una frase proverbial catalana, todavía viva en la actualidad, que Jaume Roig amplía con los nombres que añade. Si Vila-Seca y Santa Creu, posiblemente introducidos para facilitar la rima, no se pueden identificar con exactitud, pues existen diversas poblaciones así llamadas en tierras de la antigua Corona de Aragón, la Volta d'en Torra corresponde al lugar en el que estaba situado uno de los dos burdeles de Barcelona, documentado desde finales del siglo XIV ${ }^{38}$. "Pont Trencat" alude a otro topónimo urbano célebre por sus prostíbulos, pero ya no de Barcelona sino de Aviñón. La calle del Pont Trouca ("carreria Pontis Traucati") concentraba en el siglo XIV parte de las casas de prostitución de esta ciudad ${ }^{39}$. Pero es que, además, nos consta igualmente que en Aviñón - la ciudad de los papas que Petrarca llamaba la Babilonia de Occidente-, existía una casa de baños conocida también como Pont Trouca ${ }^{40}$. De nuevo, pues, los baños se relacionan directamente con la sexualidad y, por lo tanto, con el pecado, con el mal.

\section{EPILOGO: \\ DECADENCIA Y CAMBIO DURANTE EL RENACIMIENTO}

Resulta muy significativo que esta relación penetre el discurso, aunque literario, de un médico universitario tan comprometido como Jaume Roig, que murió en 1478. Hemos visto como ya a finales del siglo XIV diversos autores se hacen eco de algunas matizaciones en el discurso médico favorable al baño, apuntando hacia una limitación de su práctica. Roig es un continuador lógico de esta tendencia y a la vez un testimonio de la incidencia de estos puntos de vista en el propio estamento médico. Se preparaba una convergencia entre las posiciones de los moralistas y las de los médicos, pero todavía faltaba el factor que los uniera. Este factor de unión llegó con una fuerza terrible a partir de la última década del siglo XV.

En efecto, las enfermedades venéreas desatadas en Europa durante la transición del siglo XV al XVI proporcionaron la cobertura "científica" que faltaba a las posiciones más intransigentes. Los médicos afirmaron que el baño no tenía porqué tener acciones tan beneficiosas sino que, por el contrario, al debilitar el cuerpo y abrir los poros, podía predisponerlo ante la enfermedad. Los médicos se sumaban así a la ofensiva de los moralistas contra los baños públicos, especialmente si éstos eran mixtos.

\footnotetext{
${ }^{38} \mathrm{M} . \mathrm{T}$. VINYOLES, Història de les dones a la Catalunya medieval, Vic-Lleida, Eumo-Pagès, 2005, p. 218.

${ }^{39} \mathrm{P}$. PANSIER, Dictionnaire des anciennes rues d'Avignon, Aviñón, J. Roumanille, 1930 [reimpr.: Marsella, Laffite, 1979], p. 181 [véase también: hittp://www.up.univ$\mathrm{mrs} . \mathrm{fr} /$ tresoc/libre/integral/libr0050.pdf].

${ }^{40}$ Rossiaud, La prostituzione nel Medioevo, p. 14.
} 
Este estado de opinión se combinó pronto, al menos en los países de la Europa mediterránea occidental, con un tercer y todavía más poderoso ataque contra la cultura del baño: las exigencias uniformistas de las nuevas monarquías autoritarias que, con temibles instrumentos políticos y religiosos, persiguieron indiscriminadamente el simbolismo ritual que el baño tenía en las minorías culturales y religiosas, es decir, judíos y moriscos.

Como consecuencia de esta triple ofensiva, moral, médica y política, los baños públicos fueron clausurados por doquier, primero los fríos y en una segunda fase los termales. Estos pudieron resistir durante más tiempo gracias a su cohartada terapéutica, pero también acusaron los efectos de aquella ofensiva. Así, por ejemplo, en Caldes de Montbui, la más concurrida de las villas termales catalanas, durante el siglo XVI se suprimió el carácter mixto de las piscinas públicas, apartando de la vista incluso la que pasó a ser usada por las mujeres. Pero tanto ésta como la piscina mayor, la que fue utilizada por los hombres, fueron clausuradas a mediados del siglo XVII. Los bañistas que acudían a esta localidad en busca de una cura termal tuvieron que conformarse desde entonces sólo con las otras dos opciones que habían convivido durante siglos con las piscinas públicas: las casas de baños privadas, asequibles para una parte de la población, y el hospital de pobres.

Los efectos de esa triple ofensiva no se limitaron al ámbito público, sino que invadieron la esfera privada y la propia práctica regular del baño higiénico fue contemplada con sospecha. Se inició así la época del Renacimiento y de la Modernidad: la época de los perfumes, de los polvos y de las pelucas. En cuanto al baño terapéutico, termal, aunque continuaba siendo médicamente valorado, pasaba a ser regulado, controlado: los moralistas habían vencido.

Fecha de recepción del artículo: octubre 2008.

Fecha de aceptación y versión final: abril 2009. 